\title{
PENGGESER FASA MIKROSTRIP 90 DERAJAT UNTUK AIRPORT SURVEILLANCE RADAR (ASR) S-BAND
}

\author{
Yustina Wahyu Andika ${ }^{1}$, Levy Olivia Nur ${ }^{2}$, Yuyu Wahyu ${ }^{3}$ \\ 1,2,3 Fakultas Teknik Elektro, Universitas Telkom \\ 1yustinandika@gmail.com, ${ }^{2}$ levy.olivia@telkomuniversity.ac.id, \\ 3 yuyu.wahyu@lipi.go.id
}

\begin{abstract}
Abstrak
Pada jurnal ini dirancang sebuah microstrip passive phase shifter berbentuk meander coupled- line yang dapat di implementasikan untuk menggeser fasa sejauh 90 sehingga dapat memudahkan dalam sistem pengarahan antena. Antena dirancang di atas substrat FR-4 dengan nilai permitivitas relatif 4.6 pada frekuensi S-Band (3 GHz), yaitu frekuensi yang digunakan pada Airport Surveillance Radar yang berfungsi untuk memantau pergerakan pesawat saat masuk, keluar atau hanya melintasi wilayah bandara tertentu. Metode yang digunakan adalah Schiffmans phase shifter sebagai acuan perancangan. Pada jurnal ini, direalisasikan microstrip passive phase shifter dengan return loss untuk S11 sebesar -14.7 dB dan pada S22 sebesar -14.6 dB. Sedangkan nilai fasanya senilai 97.22 untuk S12 dan 92.56 untuk S21.
\end{abstract}

Kata Kunci: Mikrostrip, Passive phase shifter, Radar, S-Band

\begin{abstract}
In this paper we designed a microstrip passive phase shifter with meander coupled-line shaped that can be implemented to shift the phase as far as 90 so it can ease in the antenna alignment system. The antenna is designed on a FR-4 substrate with a relative permittivity value of 4.6 at the $\mathrm{S}$-Band frequency $(3 \mathrm{GHz})$, which is used on the Airport Surveillance Radar that serves to monitor the movement of the aircraft when entering, exiting or just crossing certain airport areas. The method used is Schiffman's phase shifter as a reference design. In this journal, microstrip passive phase shifter is fabricated with return loss for S11 of -14.7 $\mathrm{dB}$ and $-14.6 \mathrm{~dB}$ at $\mathrm{S22}$. While the value of the phase shift is 97.22 for $\mathrm{S12}$ and $\mathbf{9 2 . 5 6}$ for $\mathrm{S21}$.
\end{abstract}

Key Words: Mikrostrip, Passive phase shifter, Radar, S-Band

\section{Pendahuluan}

Teknik beam steering pada perancangan antena saat ini sedang mendapatkan perhatian, terutama untuk komunikasi dan aplikasi radar. Hal ini berkaitan dengan meningkatnya penggunaan dari frekuensi radio (RF) yang menuntut terminalnya mampu untuk mengarahkan pancaran gelombang yang diradiasikannya secara adaptif. Pada sistem radar, fitur pengarahan ini sangat dibutuhkan untuk menentukan arah dari target [1]. Bahkan, sistem radar yang modern seperti pada Airport Surveillance Radar (ASR) akan membutuhkan kontrol khusus untuk pengarahan pancaran gelombang dan direktivitas untuk meningkatkan kemampuan coverage dan tracking [2]. Teknik beam steering dapat dilakukan secara elektronik maupun mekanik. Namun, teknik mekanik membutuhkan sistem positioning fisik yang membutuhkan biaya yang besar, serta membutuhkan perhitungan yang presisi karena dijalankan secara manual.
Untuk mengatasinya, diperlukan suatu teknik pengarahkan antena tanpa membutuhkan gerakan mekanik dari sistem antena. Microwave phase shifter merupakan salah satu komponen yang sudah banyak digunakan pada sistem microwave circuit seperti sistem phased-array antenna, sistem komunikasi phase modulation dan aplikasi-aplikasi industri lainnya. Phase shifter yang dicetuskan oleh Schiffman merupakan tipe yang atraktif karena daya gunanya yang efektif serta menggunakan komponen pasif.

Pada Jurnal ini akan dirancang suatu passive phase shifter untuk pergeseran fasa sebesar 90 pada Airport Surveillance Radar S-Band secara sederhana supaya mudah untuk difabrikasi dan ekonomis, tetapi tetap memiliki performansi yang baik. Jenis antena yang akan digunakan berupa mikrostrip dengan bahan FR-4 yang mudah didapatkan di pasaran [3]. Pergeseran fasa yang digunakan adalah 90 karena sudut ini dibutuhkan dan cukup sering digunakan dalam sistem pergeseran fasa 
radar. Selain itu, desain yang dihasilkannya nanti dapat dijadikan acuan dasar untuk mendesain phase shifter dengan pergeseran sudut fasa lainnya.

Teknik beam steering pada perancangan antena saat ini sedang mendapatkan perhatian, terutama untuk komunikasi dan aplikasi radar. Hal ini berkaitan dengan meningkatnya penggunaan dari frekuensi radio (RF) yang menuntut terminalnya mampu untuk mengarahkan pancaran gelombang yang diradiasikannya secara adaptif. Pada sistem radar, fitur pengarahan ini sangat dibutuhkan untuk menentukan arah dari target [1]. Bahkan, sistem radar yang modern seperti pada Airport Surveillance Radar (ASR) akan membutuhkan kontrol khusus untuk pengarahan pancaran gelombang dan direktivitas untuk meningkatkan kemampuan coverage dan tracking [2]. Teknik beam steering dapat dilakukan secara elektronik maupun mekanik. Namun, teknik mekanik membutuhkan sistem positioning fisik yang membutuhkan biaya yang besar, serta membutuhkan perhitungan yang presisi karena dijalankan secara manual.

Untuk mengatasinya, diperlukan suatu teknik pengarahkan antena tanpa membutuhkan gerakan mekanik dari sistem antena. Microwave phase shifter merupakan salah satu komponen yang sudah banyak digunakan pada sistem microwave circuit seperti sistem phased-array antenna, sistem komunikasi phase modulation dan aplikasi-aplikasi industri lainnya. Phase shifter yang dicetuskan oleh Schiffman merupakan tipe yang atraktif karena daya gunanya yang efektif serta menggunakan komponen pasif.

Pada Jurnal ini akan dirancang suatu passive phase shifter untuk pergeseran fasa sebesar 90 pada Airport Surveillance Radar S-Band secara sederhana supaya mudah untuk difabrikasi dan ekonomis, tetapi tetap memiliki performansi yang baik. Jenis antena yang akan digunakan berupa mikrostrip dengan bahan FR-4 yang mudah didapatkan di pasaran [3]. Pergeseran fasa yang digunakan adalah $90^{\circ}$ karena sudut ini dibutuhkan dan cukup sering digunakan dalam sistem pergeseran fasa radar. Selain itu, desain yang dihasilkannya nanti dapat dijadikan acuan dasar untuk mendesain phase shifter dengan pergeseran sudut fasa lainnya.

\section{Dasar Teori}

\subsection{Antena Phased Array}

Antena Phased Array merupakan suatu sistem antena yang terdiri dari beberapa elemen yaitu elemen antena, amplifier dan phase shifter yang saling terhubung dan menggunakan variabel fasa atau pengontrolan time delay pada setiap elemen antenanya untuk memindai beam. Teknik array digunakan untuk menghasilkan beam yang dapat dipindai secara elektronik. Teknik beam steering dengan phase shifter pada antena phased array prinsipnya adalah pengarahan tidak dilakukan dengan rotasi fisik untuk mengubah arah dari -beam-nya, tetapi beam steering dicapai dengan mengubah amplitudo dan fasa dari sinyal pada masing-masing elemen. Pada sistem phased array, nilai fasa relatif dari elemen-elemennya diubah dengan cara tertentu, salah satunya dengan penggunaan phase shifter sehingga main beam pada pola radiasinya menunjukkan arah yang ditargetkan [4].

\subsection{Airport Surveillance Radar (ASR)}

Airport Surveillance Radar (ASR) atau radar pengawas udara merupakan radar yang digunakan untuk memantau pergerakan pesawat komersial pada saat memasuki/keluar wilayah bandara tertentu atau hanya melintasi suatu wilayah udara bandara. ASR terdiri dari dua bagian, yaitu primer dan sekunder. Bagian primernya bekerja pada frekuensi S-Band, sedangkan bagian sekundernya bekerja pada frekuensi L-Band.

Menurut Federal Aviation Administration (Departemen Transportasi Amerika Serikat), teknologi yang saat ini sedang digunakan dan dikembangkan adalah ASR-11, yang menggantikan teknologi ASR sebelumnya. . Pada ASR-11 diterapkan six level national weather service dan weather capability yang mampu menciptakan level kewaspadaan dan kesadaran yang lebih tinggi untuk masing-masing pilot dan controllers ketika pesawat melintasi wilayah bandara. Perancangan desain phase shifter dilakukan berdasarkan spesifikasi ASR untuk menentukan setiap parameter dan dimensi yang ditargetkan. Frekuensi yang digunakan untuk merancang phase shifter adalah frekuensi antena primer dari ASR yang bekerja pada frekuensi S-Band.

\subsection{Frekuensi S-Band}

S-Band merupakan salah satu bagian dari pita gelombang mikro spektrum elektromagnetik yang didefinisikan oleh standar IEEE untuk gelombang radio dengan frekuensi yang berkisar antara 2 sampai $4 \mathrm{GHz}$, melintasi batas konvensional antara UHF dan SHF pada 3,0 GHz. S-Band digunakan oleh radar cuaca, radar kapal permukaan, dan beberapa satelit komunikasi, terutama yang digunakan oleh NASA untuk berkomunikasi dengan Space Shuttle dan Stasiun Antariksa Internasional [2].

\subsection{Phase Shifter}

Phase shifter merupakan suatu alat yang mampu menggeser suatu fasa gelombang elektromagnetik dengan frekuensi tertentu ketika merambat melalui saluran transmisi. Dalam berbagai bidang elektronik, phase shifter digunakan untuk mengubah fasa sinyal.

Aplikasi phase shifter biasanya digunakan pada diskriminator fasa, jaringan beam forming, power divider, linearisasi power amplifier, dan antena phased array [5]. Secara umum, phase shifter memiliki dua 


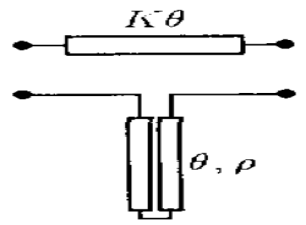

Gambar 1. Desain Standard Schiffman Phase Shifter

port, yaitu input dan output dengan parameter hamburan ideal ditunjukkan pada Persamaan1.

$$
s=\left(\begin{array}{cc}
0 & e^{j \theta} \\
e^{j \theta} & 0
\end{array}\right),
$$

Nilai $\theta$ menunjukkan respon fasa yang dapat diatur oleh input instruksi yang diberikan. Phase shifter bersifat analog jika dikontrol oleh tegangan atau arus yang kontinu dan menghasilkan respon fasa yang kontinu. Sedangkan, phase shifter digital dikontrol oleh tegangan atau arus diskrit dan menghasilkan respon fasa diskrit pada nilai tertentu.

\subsection{Schiffman Phase Shifter}

Pada tahun 1958 Bernard Schiffman mempublikasikan untuk pertama kalinya suatu phase shifter menggunakan wavelength coupler $\lambda / 4$ yang menghasilkan respons flat wideband dari pergeseran fasa. Schiffman phase shifter terdiri dari sebuah coupled section dan uniform transmission line yang berfungsi untuk menghasilkan pergeseran fasa [6]. Pemilihan panjang lintasan dan derajat kopling yang tepat, maka dapat dihasilkan pergeseran fasa yang konstan pada suatu bandwidth yang lebar.

\subsection{Meander-line Phase Shifter}

Bagian dari coupled-line pada struktur meander akan dibagi menjadi dua atau lebih, dengan nilai electrical lenght yang sama, tetapi dengan nilai impedansi karakteristik yang berbeda.

Untuk pendekatan perhitungan phase shifter $90^{\circ}$ dengan dua bagian $(\mathrm{n}=2)$, masing-masing bagian diberikan nilai panjang mendekati $45^{\circ}$ pada frekuensi tengah. Acuan yang digunakan adalah meander ideal yang memiliki nilai electrical length $\left(\theta_{i}\right)$ yang sama untuk mode ganjil dan genapnya, sehingga dapat dinyatakan oleh persamaan 2 [7].

$$
\begin{gathered}
z_{e i}=-j Z_{e} \cot \theta_{i}, \text { (genap), } \\
z_{o i}=j Z_{o} \tan \theta_{i} \text { (ganjil), }
\end{gathered}
$$

Nilai $\theta_{i}$ didapatkan dari rata-rata aritmatik $\theta_{e} \operatorname{dan} \theta_{o}$.

$$
\theta_{i}=\frac{\theta_{e}+\theta_{o}}{2} .
$$

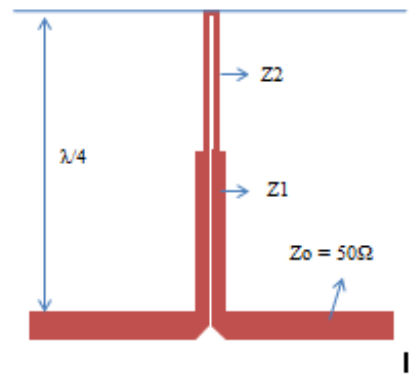

\section{Gambar 2. Stepped Impedance Meander Line Microstrip Phase Shifte}

Pada frekuensi tengah, diasumsikan bahwa $\theta_{e}=\theta_{e c}$ dan $\theta_{o}=\theta_{o c}$, serta $\theta_{i}=90^{\circ}$, sehingga

$$
90^{\circ}=\frac{\theta_{e}+\theta_{o}}{2},
$$

maka, didapatkan rasio

$$
\frac{\theta_{e}}{\theta_{o}}=\frac{\theta_{e c}}{\theta_{o c}} .
$$

Sedangkan formulasi untuk menentukan nilai impedansi input untuk meander dua bagian $(\mathrm{n}=2)$ adalah sebagai berikut.

$$
\begin{aligned}
& Z_{e 1}=\frac{1+\alpha_{e 1}}{\beta_{e 1}}, Z_{e 2}=\alpha_{e 1} \times Z_{e 1}, \\
& Y_{o 1}=\frac{1+\alpha_{o 1}}{\beta_{o 1}}, Y_{o 2}=\alpha_{o 1} \times Y_{o 1},
\end{aligned}
$$

Untuk menentukan nilai $\alpha_{e 1}, \beta_{e 1}, \alpha_{o 1}$ dan $\beta_{o 1}$ digunakan pendekatan berikut.

$$
\alpha_{e 1}=\tan ^{2} \frac{\theta_{e c}}{2}, \beta_{e 1}=\frac{\theta_{e c}}{90^{\circ}} \cos ^{-2} \frac{\theta_{e c}}{2} \text { (genap) }
$$

$$
\alpha_{o 1}=\tan ^{2} \frac{\theta_{o c}}{2}, \beta_{o 1}=\frac{\theta_{o c}}{90^{\circ}} \cos ^{-2} \frac{\theta_{o c}}{2} \text { (ganjil) }
$$

Formulasi dan desain stepped impedance ini diharapkan dapat menghasilkan keluaran yang matching saat diterapkan.

3. Perancangan dan Realisasi

3.1 Diagram Alir proses Realisasi Antena Tekstil

3.2 Gambar Perancangan Antena Berdasarkan Perhitungan

\subsection{Perancangan Antena Pada CST}

Hasil perhitungan di atas digunakan sebagai patokan awal dalam memulai tahapan simulasi. Simulasi disini bertujuan untuk mendapatkan data performansi 


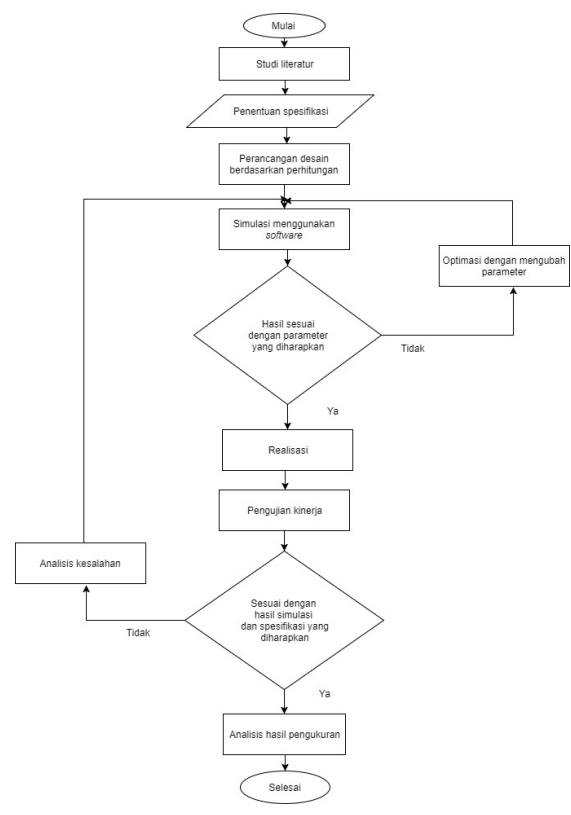

Gambar 3. Diagram Alir Proses Perancangan dan Realisasi Microstrip Phase Shifter

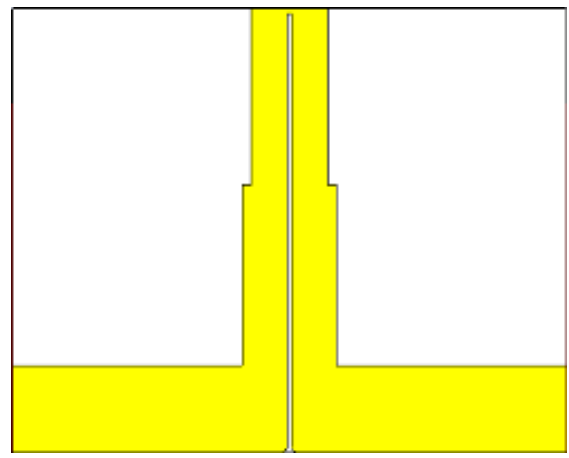

Gambar 4. Gambar tampak depan Prototipe Antena tekstile

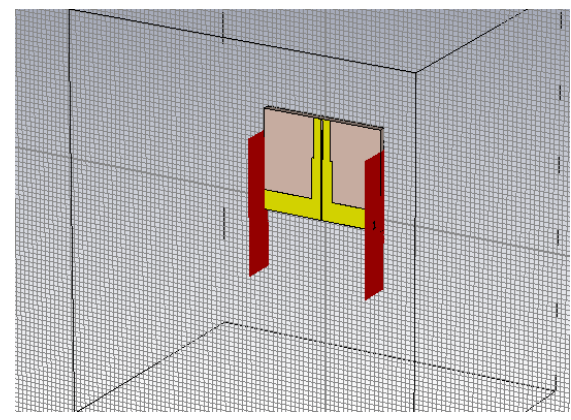

Gambar 5. Gambar tampak belakang Prototipe Antena tekstile
Tabel 1. Dimensi Perhitungan

\begin{tabular}{|l|l|l|}
\hline No. & Parameter & Nilai $(\mathrm{mm})$ \\
\hline 1. & A & 25 \\
\hline 2. & P & 0.2 \\
\hline 3. & P1 & 0.055 \\
\hline 4. & P2 & 0.05 \\
\hline 5. & T1 & 7.281 \\
\hline 6. & T2 & 7.19 \\
\hline 7. & Z0 & 2.74 \\
\hline 8. & Z1 & 2.45 \\
\hline 9. & Z2 & 1.66 \\
\hline 10. & Z3 & 0.27 \\
\hline
\end{tabular}

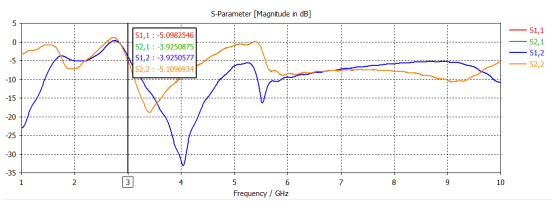

Gambar 6. Gambar Grafik Nilai Return Loss Simulasi 1

phase shifter dan juga sebagai media koreksi atau optimasi sehingga didapatkan hasil yang terbaik yang sesuai dengan spesifikasi awal.

\subsubsection{Simulasi dan optimasi}

Hasil perhitungan yang didapatkan disimulasikan menggunakan sofware CST sebagai dasar awal pembuatan desain untuk melihat performansi phase shifter. Untuk mendapat antena yang sesuai dengan spesifikasi awal dilakukan beberapa kali optimasi hingga memperoleh ukuran yang tepat. Berikut hasil simulasi awal berdasarkan dimensi pada Tabel 1 .

Dari Gambar 6 terlihat bahwa nilai Return Loss pada frekuensi S-Band untuk S1,1 dan S2,2 adalah pada angka -5. Hasil ini belum memenuhi spesifikasi yang ditentukan, sehingga perlu dilakukan optimasi pada nilai dimensi phase shifter untuk mendapatkan hasil yang diharapkan.

Karena spesifikasi antena pada simulasi 1 belum sesuai dengan hasil yang diharapkan, maka dilakukan optimasi terhadap dimensi phase shifter.

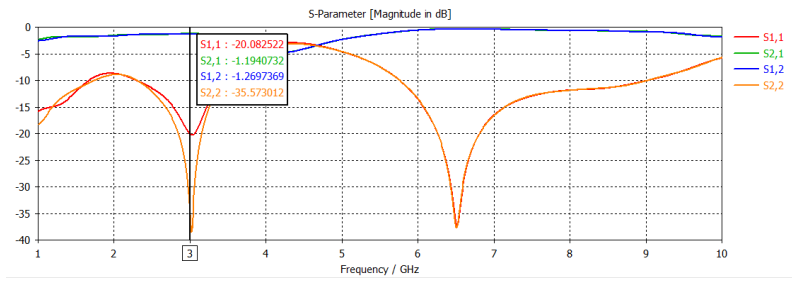

Gambar 7. Gambar grafik nilai return loss simulasi 2 
Tabel 2. Dimensi Perhitungan Optimasi

\begin{tabular}{|l|l|l|}
\hline No. & Parameter & Nilai $(\mathrm{mm})$ \\
\hline 1. & A & 20 \\
\hline 2. & P & 0.2 \\
\hline 3. & P1 & 0.205 \\
\hline 4. & P2 & 0,252 \\
\hline 5. & T1 & 6.55 \\
\hline 6. & T2 & 5.05 \\
\hline 7. & Z0 & 2.79 \\
\hline 8. & Z1 & 3.65 \\
\hline 9. & Z2 & 2.66 \\
\hline 10. & Z3 & 0.22 \\
\hline
\end{tabular}

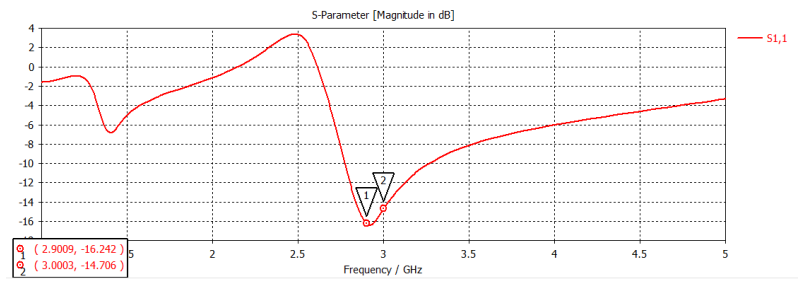

Gambar 8. Return Loss S11 Setelah Optimasi

Berdasarkan Gambar 7, terlihat bahwa nilai Return Loss sudah terpenuhi, yaitu pada $-20 \mathrm{~dB}$ dan $-35 \mathrm{~dB}$, tetapi nilai fasanya masih belum memenuhi kriteria yang diinginkan. Oleh karena itu, dilakukan beberapa kali optimasi lagi untuk mendapatkan hasil yang paling mendekati spesifikasi yang diharapkan. Pada percobaan sebelumnya, ukuran dimensi p1 dan p2 yang merepresentasikan perpotongan antara coupled line sangatlah kecil, yaitu pada 0.05 dan $0.055 \mathrm{~mm}$, sehingga proses fabrikasinya cukup sulit. Oleh sebab itu, dilakukan optimasi untuk menyesuaikan ukuran dimensi agar mengurangi tingkat kesulitan dalam proses fabrikasinya. Berikut ini merupakan dimensi akhir setelah dilakukan beberapa kali optimasi.

Berikut hasil simulasi setelah di optimasi kembali :

Setelah dioptimasi, grafik S11 untuk nilai Return Loss yang dihasilkan oleh dimensi yang tertera pada Tabel 2 menunjukkan angka yang telah memenuhi kriteria, yaitu pada $-16.2 \mathrm{~dB}$ pada frekuensi $2.9 \mathrm{GHz}$ dan $-14.7 \mathrm{~dB}$ pada frekuensi $3 \mathrm{GHz}$.

Gambar 9 menunjukkan nilai respon pergeseran

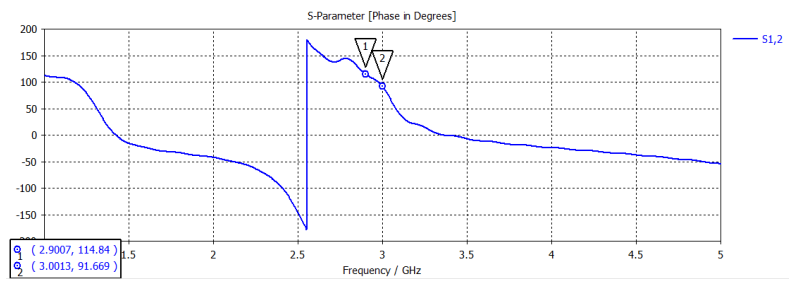

Gambar 9. Fasa S12 setelah optimasi

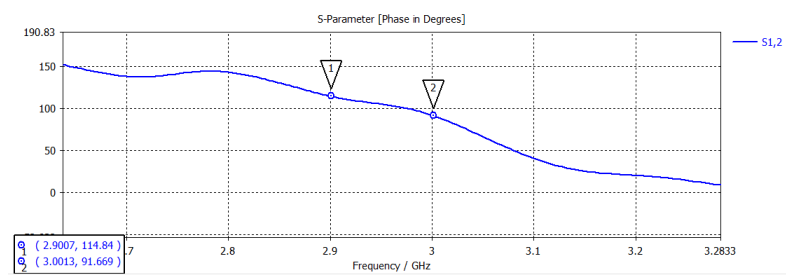

Gambar 10. Grafik pergeseran fasa S12 pada 2.9-3.1 $\mathbf{G H z}$

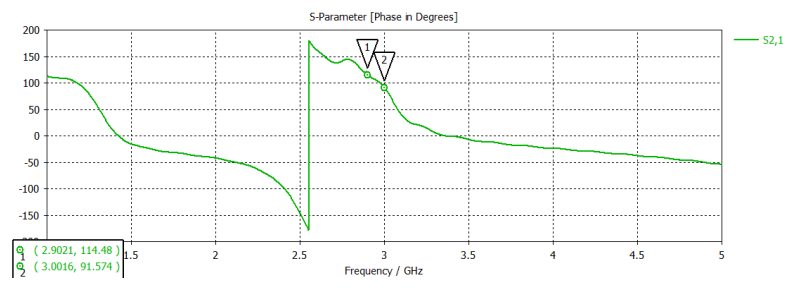

Gambar 11. Fasa S21 setelah optimasi

fasa pada grafik S12 yang terjadi pada ouput port dengan phase shifter $90^{\circ}$ pada frekuensi $2.9 \mathrm{GHz}$ dan $3 \mathrm{GHz}$. Grafik yang dihasilkan sudah cukup flat dan jarak pergeseran dari $2.9 \mathrm{Ghz}$ ke $3 \mathrm{GHz}$ berhasil dipersempit, seperti terlihat pada Gambar 10

Gambar 11 menunjukkan nilai respon pergeseran fasa pada grafik S21 yang terjadi pada ouput port dengan phase shifter $90^{\circ}$ pada frekuensi $2.9 \mathrm{GHz}$ dan $3 \mathrm{GHz}$. Grafik yang dihasilkan sudah cukup flat dan jarak pergeseran dari $2.9 \mathrm{Ghz}$ ke $3 \mathrm{GHz}$ berhasil dipersempit, seperti terlihat pada Gambar 12.

\subsection{Pemodelan Prototipe Antena}

Setelah dilakukan simulasi untuk mendapatkan hasil parameter yang sesuai spesifikasi, maka prototype phase shifter mikrostrip difabrikasi sesuai dengan ukuran simulasi yang telah dirancang.

\section{PENGUKURAN DAN ANALISIS}

\subsection{Analisis Hasil pengukuran Return Loss}

Berikut merupakan hasil pengukuran return loss S11 dan S22.

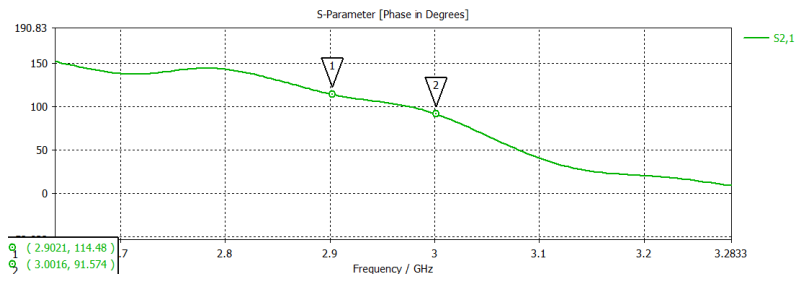

Gambar 12. Grafik pergeseran fasa S21 pada 2.9-3.1 GHz 


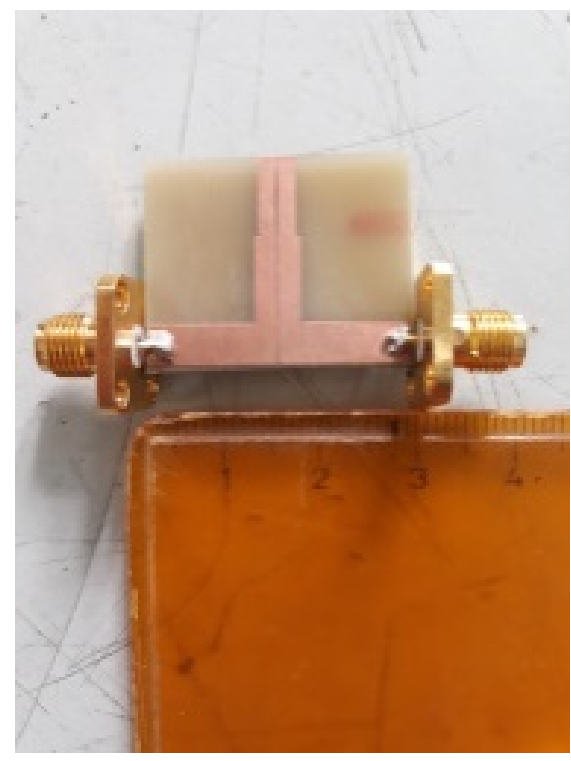

Gambar 13. Pemodelan prototipe antena yang direalisasikan

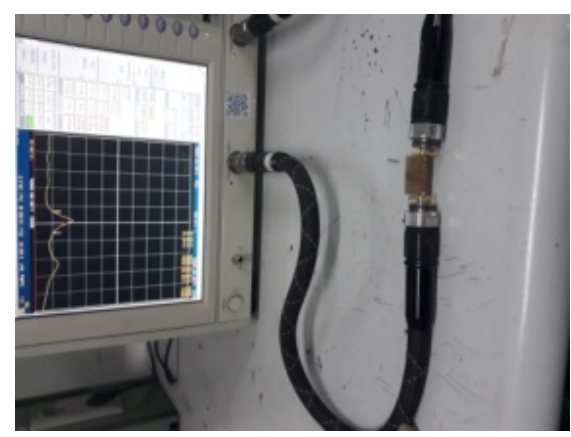

Gambar 14. Pengukuran phase shifter

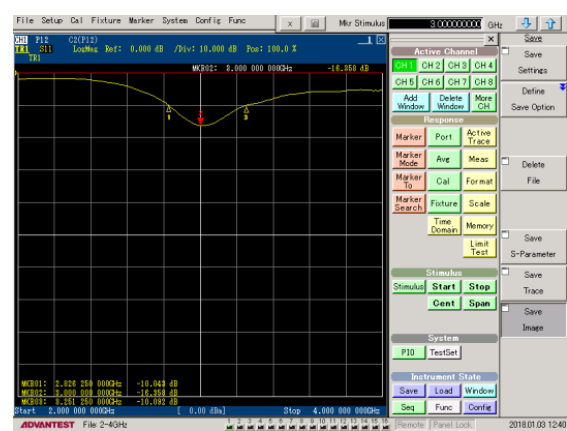

Gambar 15. Pengukuran return loss S11

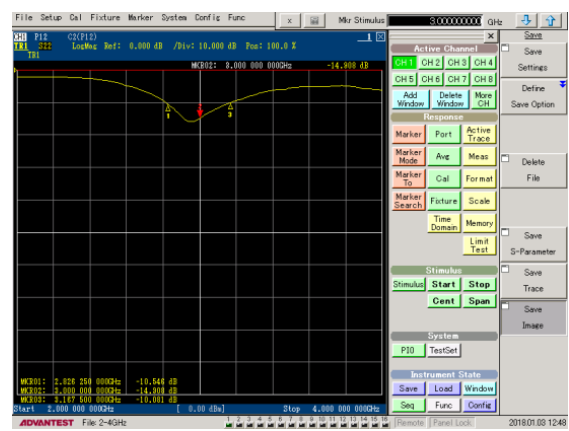

Gambar 16. Pengukuran return loss S22

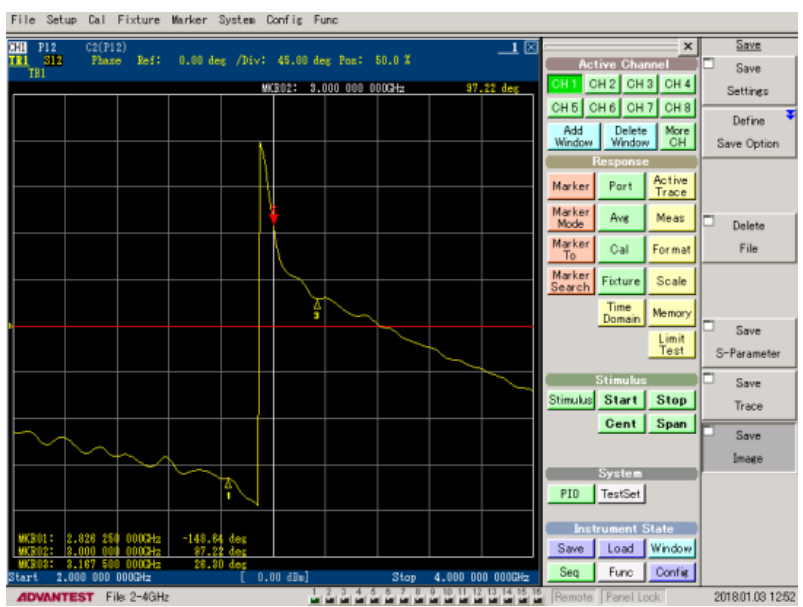

Gambar 17. Pengukuran fasa S12

Berdasarkan Gambar 15, nilai return loss S11 sudah memenuhi spesifikasi yang diharapkan $(\leq-10 \mathrm{~dB})$ yaitu pada nilai $-16.358 \mathrm{~dB}$. Range frekuensi nilai return loss dengan nilai $\leq-10 \mathrm{~dB}$ ada pada $2,8-3,1 \mathrm{GHz}$.

Berdasarkan Gambar 16, nilai return loss S22 sudah memenuhi spesifikasi yang diharapkan $(\leq-10 \mathrm{~dB})$ yaitu pada nilai $-14.908 \mathrm{~dB}$. Range frekuensi nilai return loss dengan nilai $\leq-10 \mathrm{~dB}$ ada pada $2,8-3,1 \mathrm{GHz}$.

\subsection{Analisis Hasil pengukuran fasa}

Berdasarkan Gambar 17 dan 18, nilai fasa S12 pada frekuensi $3 \mathrm{GHz}$ adalah $97.22^{\circ}$. Sedangkan, pada frekuensi 2.8 adalah sebesar $146.64^{\circ}$ dan pada frekuensi 3.1 adalah sebesar $26.3^{\circ}$. Sedangkan untuk S21 nilai fasanya adalah $92.56^{\circ}$ pada $3 \mathrm{GHz}, 151.18^{\circ}$ pada 2.8 $\mathrm{GHz}$ dan $30.38^{\circ}$ untuk frekuensi $3.1 \mathrm{GHz}$. Grafik fasa yang dihasilkan menunjukkan garis yang belum terlalu flat, tetapi untuk frekuensi S-Band $(3 \mathrm{GHz})$ nilainya sudah cukup mendekati.

\subsection{Impedansi phase shifter}

Nilai impedansi untuk Z11 adalah $50.924 \Omega$, sehingga telah sesuai dengan spesifikasi yang diharapkan. Sedangkan pada Gambar 20 terlihat bahwa 


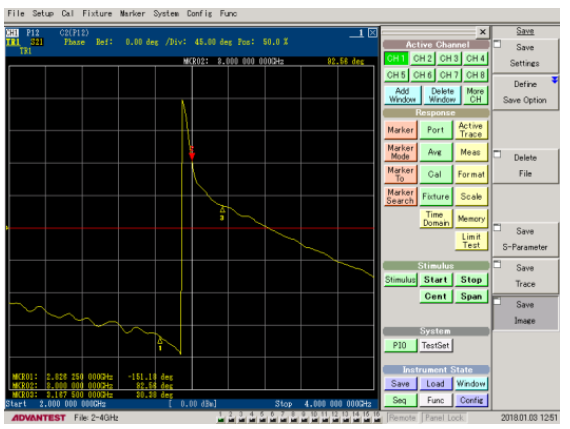

Gambar 18. Pengukuran fasa S21

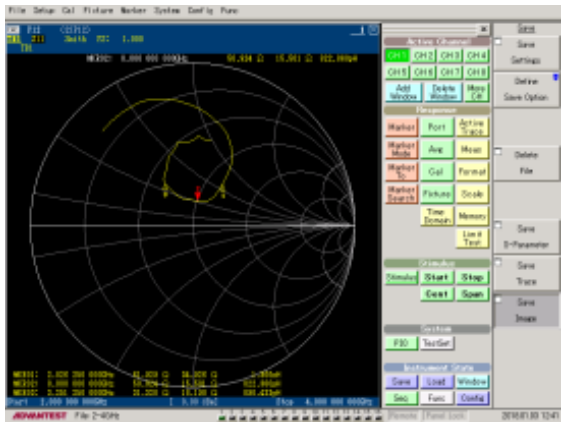

Gambar 19. Pengukuran impedansi Z11

nilai impedansi Z22 adalah $39.85 \Omega$, sehingga memungkinkan masih terdapatnya fenomena tidak matching tetapi masih pada nilai yang mendekati impedansi yang diharapkan.

\subsection{Analisis Hasil Pengukuran}

Berikut ini merupakan tabel perbandingan hasil simulasi perancangan phase shifter menggunakan software CST dan pengukuran berdasarkan fabrikasi.

Berdasarkan tabel dan gambar-gambar hasil pengukuran terlihat bahwa beberapa parameter telah memenuhi spesifikasi, seperti return loss dan impedansi. Tetapi, nilai pergeseran fasa hanya mampu mencapai level mendekati, belum sesuai secara sempurna. Hal ini dapat disebabkan oleh berbagai faktor, diantaranya

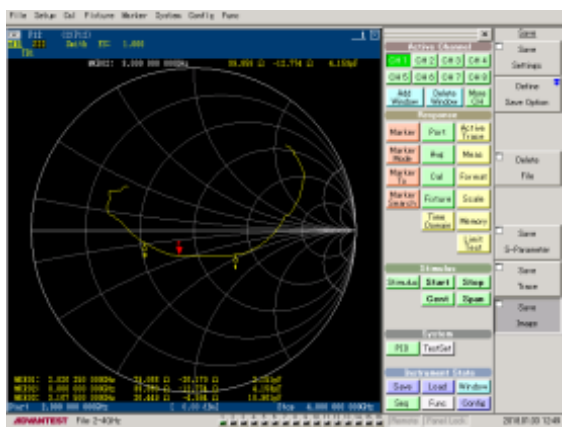

Gambar 20. Pengukuran impedansi Z22
Tabel 3. Perbandingan Hasil Pengukuran

\begin{tabular}{|l|l|l|}
\hline \multicolumn{1}{|c|}{ Parameter } & \multicolumn{1}{|c|}{ Simulasi } & \multicolumn{1}{|c|}{ Pengukuran } \\
\hline $\begin{array}{l}\text { Range frekuensi } \\
\text { pada nilai return } \\
\text { loss } \leq 10 \mathrm{~dB}\end{array}$ & $2.93 \mathrm{GHz}$ & $2.83 .1 \mathrm{GHz}$ \\
\hline $\begin{array}{l}\text { Impedansi } \\
\text { masukan }\end{array}$ & $50 \Omega$ & $\begin{array}{l}50.924 \Omega \quad \\
39.858 \Omega\end{array}$ \\
\hline $\begin{array}{l}\text { Pergeseran fasa } \\
\text { pada S12 }\end{array}$ & $90^{\circ}$ & $97.22^{\circ}$ \\
\hline $\begin{array}{l}\text { Pergeseran fasa } \\
\text { pada S21 }\end{array}$ & $90^{\circ}$ & $92.56^{\circ}$ \\
\hline
\end{tabular}

adalah kesalahan pada saat fabrikasi maupun saat pengukuran karena ukuran phase shifter yang difabrikasi cukup kecil dan sifatnya sensitif terhadap perubahan ukuran dimensinya, sehingga dibutuhkan tingkat ketelitian yang tinggi pada saat proses fabrikasi maupun pengukuran.

Ketidaksempurnaan yang terjadi akibat proses fabrikasi dapat memberikan pengaruh terhadap parameter-parameter yang ditargetkan, antara lain tidak matching-nya saluran transmisi yang direpresentasikan oleh nilai impedansi yang lebih rendah dari target yang diharapkan mempengaruhi kualitas nilai return loss dan pergeseran frekuensi kerja, sedangkan gap yang kurang presisi sangat menjadikan pergeseran fasa menjadi kurang tepat sasaran. Pada implementasinya pada Airport Surveillance Radar, hal ini akan berpengaruh terhadap sudut pengarahan antenanya, karena kemungkinan nilai phase error-nya menjadi lebih tinggi, sehingga ada kemungkinan pengarahan menjadi kurang tepat sasaran pada saat akan mengarahkan pada target pesawat yang melintas pada wilayah bandara.

\section{KESIMPULAN DAN SARAN}

\subsection{Kesimpulan}

Kesimpulan yang dapat diambil dari seluruh proses perancangan dan realisasi microstrip passive phase shifter adalah sebagai berikut :

1. Berdasarkan hasil perancangan melalui simulasi software, passive phase shifter mampu bekerja pada range frekuensi $2.93 \mathrm{GHz}$ dengan nilai return loss $-14.7 \mathrm{~dB}$ untuk S11 dan -14.6 dB untuk $\mathrm{S} 22$. Sedangkan nilai pergeseran fasanya bernilai $91^{\circ}$ untuk masing-masing parameter S12 dan S21.

2. Passive phase shifter yang telah difabrikasi mampu bekerja pada range frekuensi $2.8-3.1$ $\mathrm{GHz}$ dengan nilai return loss S11 sebesar -16.35 dB, pada S22 sebesar -14.908 dB. Sedangkan nilai fasanya senilai $97.22^{\circ}$ untuk $\mathrm{S} 12$ dan $92.56^{\circ}$ untuk S21. Dengan demikian, rancangan telah mendekati kebutuhan dan sesuai dengan spesifikasi yang diharapkan, yaitu nilai return loss $\leq-10 \mathrm{~dB}$ dan pergeseran fasa mendekati $90^{\circ} .[1][2][8][5]$ 


\subsection{Saran}

Untuk mendapat performasi antena yang lebih baik, maka beberapa hal yang menjadi saran untuk penelitian selanjutnya tentang antena textile, antara lain :

1. Pemilihan bahan untuk substrat antena sebaiknya lebih diperhatikan dan disesuaikan. Bahan FR-4 yang digunakan dalam Jurnal ini bisa diganti dengan bahan lain yang memungkinkan sebagai penyusun passive phase shifter.

2. Microstrip passive phase shifter pada fasa $90^{\circ}$ masih dapat dikembangkan dengan berbagai metode dan dengan bentuk desain yang berbeda.

\section{Daftar Pustaka}

[1] M. Skolnik, Radar Handbook 2nd Edition. Boston: Artech House, 2005.

[2] A. Lestari, Radar S-Band Pertama Karya Anak Bangsa. Jakarta, 2012.

[3] A. I. Rachmansyah and A. B. Mutiara, "Designing and manufacturing microstrip antenna for wireless communication at $2.4 \mathrm{ghz}$," International Journal of Computer and Electrical Engineering, vol. 3, no. 5, pp. 670-675, 2011.
[4] V. Rabinovich and N. Alexandrov, Antenna arrays and automotive applications. Springer Science \& Business Media, 2012.

[5] I. Rosu. Phase shifters. yo3dac / va3iul. [Online]. Available: https://www.qsl.net/va3iul/

[6] B. Schiffman, "A new class of broad-band microwave 90-degree phase shifters," IRE Transactions on Microwave Theory and Techniques, vol. 6, no. 2, pp. 232-237, 1958.

[7] B. Schiek and J. Kohler, "A method for broadband matching of microstrip differential phase shifters," IEEE Transactions on Microwave Theory and Techniques, vol. 25, no. 8, pp. 666-671, 1977.

[8] Z. Zhang, Y.-C. Jiao, S.-F. Cao, X.-M. Wang, and F.-S. Zhang, "Modified broadband schiffman phase shifter using dentate microstrip and patterned ground plane," Progress In Electromagnetics Research, vol. 24, pp. 9-16, 2011. 